\title{
Validation of the Omron M3 Intellisense (HEM-7051-E) Upper Arm Blood Pressure Monitor, for Self-Measurement, according to the European Society of Hypertension International Protocol Revision 2010 in a Stage 3-5 Chronic Kidney Disease Population
}

\author{
Tekin Akpolat Emre Erdem Türkan Aydogdu \\ Department of Nephrology, Ondokuz Mayis University School of Medicine, Samsun, Turkey
}

\section{Key Words}

Arterial stiffness $\cdot$ Chronic kidney disease $\cdot$ Home blood pressure monitoring $\cdot$ Hypertension - Oscillometric sphygmomanometers $\cdot$ Validation protocols

\begin{abstract}
Background: Encouragement of home blood pressure (BP) monitoring has a great potential to improve hypertension control rates. The purpose of this study was to test validation of the Omron M3 Intellisense (HEM-7051-E) upper arm BP measuring monitor for self-measurement according to the European Society of Hypertension International Protocol revision 2010 (ESH-IP2) in stage 3-5 chronic kidney disease (CKD) patients. Methods: 66 patients having CKD stage 3-5 were included in the study. Nine consecutive measurements were made according to the ESH-IP2 protocol. Results: The Omron M3 Intellisense device fulfills the validation criteria of the ESH-IP2 for stage 3-5 CKD patients. Conclusion: Although arterial stiffness can affect accurate BP measurement, there are limited data regarding the use of automated
\end{abstract}

oscillometric devices in CKD. To our knowledge, this is the first study investigating validation of an oscillometric device in stage 3-5 predialysis CKD patients. This study validates the Omron M3 Intellisense upper arm device for stage 3-5 CKD patients. New validation studies investigating other oscillometric sphygmomanometers for CKD patients and involvement of nephrologists in these studies have great potential to increase patient care in CKD.

Copyright $\odot 2011$ S. Karger AG, Basel

\section{Introduction}

Hypertension is a major risk factor for the development and progression of chronic kidney disease (CKD) and its control has become the most important intervention in the management of all forms of CKD [1]. Strict control of hypertension is required in patients with $\mathrm{CKD}$, but failure to achieve the target blood pressure (BP), which is lower than that for the general population, is a frequent problem [2]. Active involvement of patients

\section{KARGER}

Fax +41613061234 E-Mail karger@karger.ch www.karger.com

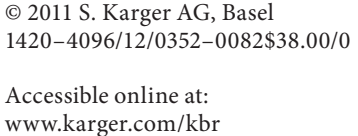

Tekin Akpolat, MD

Ondokuz Mayıs Üniversitesi, Tip Fakültesi

Nefroloji Bilim Dali

TR-55139 Samsun (Turkey)

Tel. +90 362312 1919/2189, E-Mail tekinakpolat@yahoo.com 
Fig. 1. The Omron M3 Intellisense device.

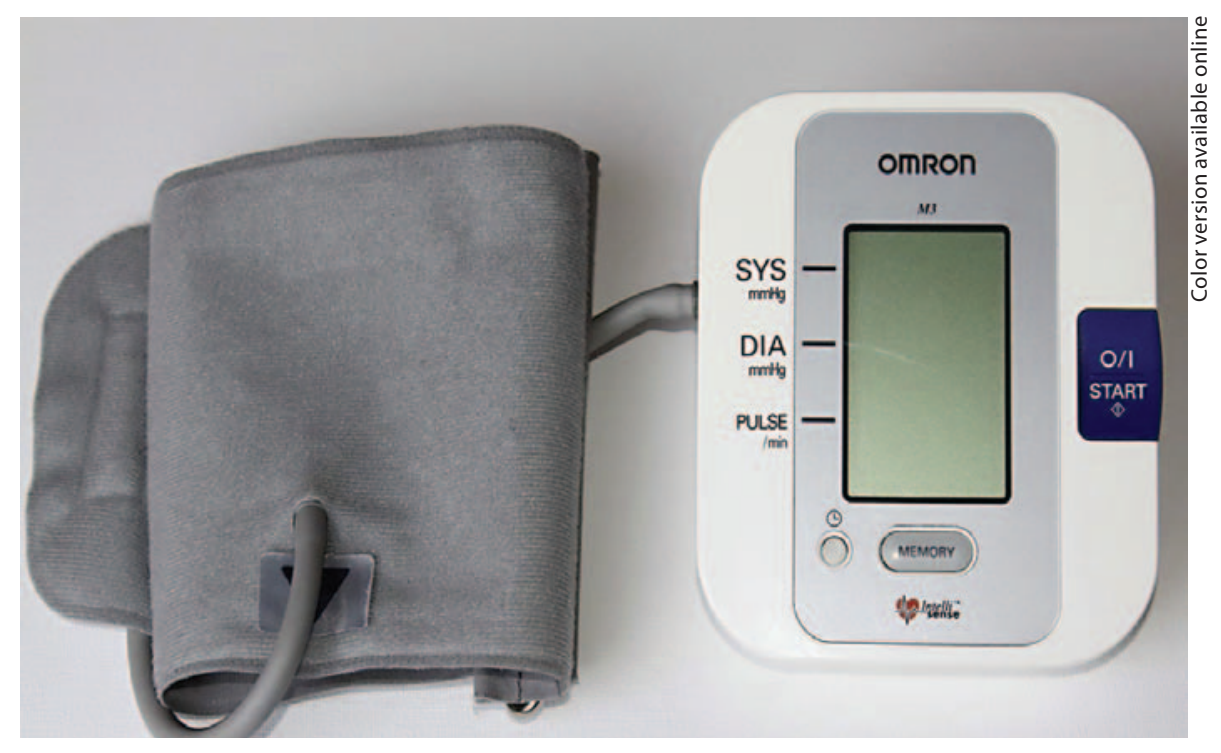

in their treatment process is a significant factor in the successful management of hypertension. Encouragement of home blood pressure monitoring (HBPM) is one of the measures that increases patient compliance with treatment and has a great potential to improve hypertension control rates [3-5]. Self-measurement of BP at home requires a precise $\mathrm{BP}$ measurement technique and an accurate sphygmomanometer [3]. Standard validation protocols [6-9] are objective guides for physicians who want to recommend an accurate device to their patients.

In order to evaluate the accuracy of devices in clinical practice, the Association for the Advancement of Medical Instrumentation (AAMI) published a validation protocol for electronic and aneroid sphygmomanometers in 1987, and this was followed in 1990 by the protocol of the British Hypertension Society (BHS); both protocols were revised in $1993[6,7]$. On the basis of these experiences, the Working Group on Blood Pressure Monitoring of the European Society of Hypertension published a simplified protocol (International Protocol) to facilitate the evaluation process in 2002 [8]. The European Society of Hypertension International Protocol was revised in 2010 (ESH-IP2) and as a consequence of improvements in technology, pass levels of devices were tightened [9]. These protocols are for the general adult population and it should not be assumed that a device that has been validated in the general population will be accurate in special populations, such as obese patients, patients with increased arterial stiffness, children or pregnant women. The purpose of this study was to test the validation of the Omron M3 Intellisense (HEM7051-E) upper arm BP measuring monitor for self-measurement, according to the ESH-IP2 in stage 3-5 CKD patients.

\section{Subjects and Methods}

\section{The Device}

The Omron M3 Intellisense device (Omron Healthcare, Kyoto, Japan) was recently validated for the general population according to the International Protocol [10]. The Omron M3 Intellisense monitor used in our study (fig. 1) was purchased from a local market. The Omron M3 Intellisense is an automated and oscillometric upper arm device for HBPM. The standard arm cuff of the device is $22-32 \mathrm{~cm}$ and a large cuff is also available for arm circumferences of $32-42 \mathrm{~cm}$. For comfortable controlled inflation without the need for pressure presetting or reinflation the device uses 'IntelliSense' technology.

\section{Patients and Recruitment}

Subjects (tables 1 and 2) were recruited from those attending the Ondokuz Mayis University School of Medicine Nephrology Clinic. All subjects participated immediately and without appointment. Participants were informed about the study. Since nearly all patients attending the clinic were on antihypertensive treatment (mean number of medications was 2.7, range 0-6), there was some difficulty in recruiting subjects with diastolic BP (DBP) in the high range. Therefore, we planned to increase the number of participants from 33 to 66 according to the ESH-IP2 


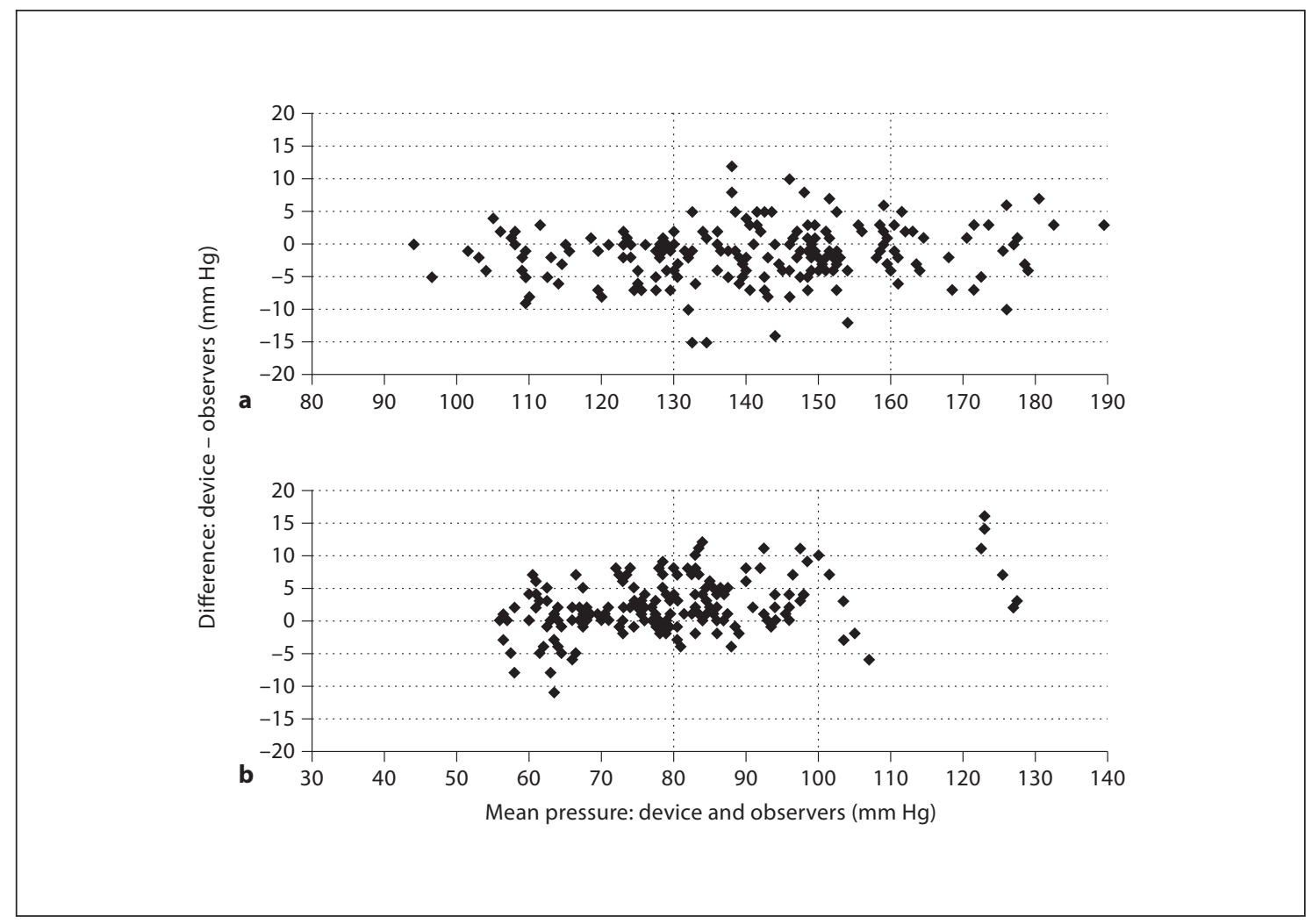

Fig. 2. Plots of BP difference (a SBP, b DBP) between the Omron M3 Intellisense readings and the mean of the two observer readings in 66 participants $(n=198)$.

Table 1. Screening and recruitment details

\begin{tabular}{lccc}
\hline & & Total & On $\mathrm{Rx}^{\mathrm{a}}$ \\
\hline Total screened & & 69 & \\
Total excluded & 3 & \\
$\quad$ Arrhythmias & $2^{\mathrm{b}}$ & \\
Poor quality sounds & 1 & \\
Observer disagreement & & $2^{\mathrm{c}}$ & \\
Total recruited & & 66 & \\
\hline SBP, mm Hg & $<90$ & 0 & 0 \\
Low & $90-129$ & 15 & 15 \\
Medium & $130-160$ & 31 & 30 \\
High & $161-180$ & 12 & 11 \\
& $>180$ & 8 & 7 \\
DBP, mm Hg & $<40$ & 0 & 0 \\
Low & $40-79$ & 29 & 29 \\
Medium & $80-100$ & 32 & 31 \\
High & $101-130$ & 4 & 3 \\
& $>130$ & 1 & 1 \\
\hline
\end{tabular}

${ }^{\mathrm{a}}$ On treatment. ${ }^{\mathrm{b}}$ Detected during BP measurement. ${ }^{\mathrm{c}}$ Repeated and the subjects were recruited.
Table 2. Subject details

$\begin{array}{ll}\text { Sex } & \\ \quad \text { Male/female } & 45 / 21 \\ \text { Age, years }{ }^{\mathrm{a}} & \\ \quad \text { Range } & 30-85 \\ \text { Mean } \pm \text { SD } & 62.7 \pm 12.5 \\ \text { Arm circumference, cm } & 23-32 \\ \quad \text { Range } & 28.5 \pm 2.6 \\ \quad \text { Mean } \pm \text { SD } & \\ \text { Cuff for test device, cm } & - \\ \quad \text { Small } & 66 \\ \text { Standard }(22-32 \mathrm{~cm}) & - \\ \quad \text { Large } & \\ \text { Recruitment BP, mm Hg } & \\ \text { SBP } & 96-235 \\ \quad \text { Range } & 150.2 \pm 26.6 \\ \quad \text { Mean } \pm \text { SD } & \\ \text { DBP } & 55-131 \\ \quad \text { Range } & 82.2 \pm 14.8\end{array}$

a 31 of the subjects were older than 65 years. 
Table 3. Observer measurements in each recruitment range

\begin{tabular}{ll}
\hline SBP, mm Hg & \\
Overall range, low/high & $94 / 226$ \\
Low $(<130)$ & 61 \\
Medium $(130-160)$ & 104 \\
High $(>160)$ & 33 \\
Maximum difference & 71 \\
DBP, mm Hg & \\
Overall range, low/high & $54 / 131$ \\
Low $(<80)$ & 97 \\
Medium $(80-100)$ & 86 \\
High $(>100)$ & 15 \\
Maximum difference & 82 \\
\hline
\end{tabular}

Table 4. Observer differences

\begin{tabular}{lll}
\hline & SBP & DBP \\
\hline Observer 2-observer 1 & & \\
Range, low/high & $-4 /+4$ & $-4 /+4$ \\
Mean \pm SD & $0.8 \pm 1.5$ & $0.3 \pm 1.4$ \\
\hline
\end{tabular}

Number of repeated measurements: 2 .

Table 5. Validation results

\begin{tabular}{|c|c|c|c|c|c|c|c|}
\hline Part 1 & & $\leq 5 \mathrm{~mm} \mathrm{Hg}$ & $\leq 10 \mathrm{~mm} \mathrm{Hg}$ & $\leq 15 \mathrm{~mm} \mathrm{Hg}$ & Grade 1 & Mean & SD \\
\hline $\begin{array}{l}\text { Pass } \\
\text { requirement } \\
\text { Achieved }\end{array}$ & $\begin{array}{l}\text { Two of } \\
\text { All of } \\
\text { SBP } \\
\text { DBP }\end{array}$ & $\begin{array}{l}73 \\
65 \\
80^{\mathrm{a}} \\
78^{\mathrm{a}}\end{array}$ & $\begin{array}{l}87 \\
81 \\
96.5^{\mathrm{a}} \\
95^{\mathrm{a}}\end{array}$ & $\begin{array}{l}96 \\
93 \\
99^{\mathrm{a}} \\
98.5^{\mathrm{a}}\end{array}$ & $\begin{array}{l}\text { pass } \\
\text { pass }\end{array}$ & $\begin{array}{r}-1.3 \\
2.1\end{array}$ & $\begin{array}{l}4.3 \\
4.1\end{array}$ \\
\hline Part 2 & & $2 / 3 \leq 5 \mathrm{~mm} \mathrm{Hg}$ & $0 / 3 \leq 5 \mathrm{~mm} \mathrm{Hg}$ & & Grade 2 & & Grade 3 \\
\hline $\begin{array}{l}\text { Pass } \\
\text { requirement } \\
\text { Achieved }\end{array}$ & $\begin{array}{l}\text { SBP } \\
\text { DBP }\end{array}$ & $\begin{array}{l}\geq 24 \\
29^{\mathrm{a}} \\
27.5^{\mathrm{a}}\end{array}$ & $\begin{array}{l}\leq 3 \\
0.5^{\mathrm{a}} \\
2^{\mathrm{a}}\end{array}$ & & $\begin{array}{l}\text { pass } \\
\text { pass }\end{array}$ & & \\
\hline Part 3 & & & & & & & $\begin{array}{l}\text { result } \\
\text { pass }\end{array}$ \\
\hline
\end{tabular}

Since the number of participants was doubled (from 33 to 66), the number of measurements was divided by two for assessments.

${ }^{a}$ Numbers divided by two.

protocol. Underlying renal diseases of the 66 patients were: hypertension $(n=17)$, diabetes mellitus $(n=11)$, autosomal polycystic kidney disease $(n=7)$, glomerulonephritis $(n=5)$, renovascular disease $(n=4)$, other causes $(n=9)$, and unknown $(n=13)$. The Modification of Diet in Renal Disease (MDRD) equation was used to estimate glomerular filtration rate [11]. Mean glomerular filtration rate of the participants was $31 \mathrm{ml} / \mathrm{min}$ (range 5-58). Only patients having CKD stage 3-5 were included in the study [11]. The number of participants in stages 3,4 , and 5 were 36,16 , and 14 , respectively. Patients having a previous unsuccessful kidney transplantation (stage 5T) or being on regular hemodialysis program (stage 5D) were not included. None of the patients were pregnant or had arrhythmia, a hypertensive emergency or any acute disease.

Arterial Stiffness, Oscillometric Devices, and CKD

\section{Blood Pressure Measurements}

Twenty measurements using the tested device were carried out for familiarization. No problems were encountered. The European Society of Hypertension International Protocol revision 2010 for the validation of BP measuring devices in adults was followed precisely. The validation team consisted of two persons experienced in BP measurement. Observers had adequate hearing and sight. They viewed a CD-ROM about the BP measurement technique in their native language and were trained individually. Overseen by an independent supervisor, measurements were recorded by two observers blinded from both each other's readings and from the device readings. The participants were seated in a quiet room and BP measurements were started after a 10 - to 15min rest period. BP measurements were made on the left arm at 
the heart level in 57 subjects, whereas BP was measured on the right arm in 9 subjects because of an arteriovenous fistula on the left $\operatorname{arm}(n=7)$, left hemiplegia $(n=1)$, and a past history of graft operation on the left $(n=1)$. Nine consecutive measurements were made according to the ESH-IP2 protocol $[8,9]$. The mercury sphygmomanometer was used as the 'gold standard' and the time between readings was 30-60 s.

\section{Results}

The study results are presented in tables $2-5$ and figure 2. Since the number of participants was doubled (from 33 to 66), the number of measurements was divided by two for comparison with the general population validation study [10] in table 5. Thus the Omron M3 Intellisense device fulfills the validation criteria of the ESH-IP2 for stage 3-5 CKD patients.

\section{Discussion}

HBPM in clinical practice is a useful adjunct to conventional office measurements [12] and reimbursement for the cost of purchasing a validated sphygmomanometer could be highly cost-effective in CKD [3, 13-15]. It can be expected that every CKD patient will own an automated home sphygmomanometer in the future because HBPM is being increasingly used in many countries, is well accepted by hypertensive patients, and has many advantages [3, 5, 12-14]. The main disadvantage of automated home sphygmomanometers is their inaccuracy, but it is improving [9]. In addition, the majority of devices available in the market have not been evaluated independently for accuracy [16-18]. Indeed, Coleman et al. [18] reported that only an estimated $2 \%$ of the BP monitors currently available in the United Kingdom have been validated.

Inaccuracy may be more common in special patient groups, requiring additional validation tests. A check of individual accuracy is also required $[3,19]$. The BHS protocol described validation procedures for special groups such as pregnant women, children and the elderly, and it reduced the number of participants for special groups from 85 to 30 for devices that had been successfully validated in general population. Because the number of participants had already been decreased, the European Society of Hypertension International Protocols did not make any specific recommendations, but allowed reasonable adjustments for special groups $[8,9]$. The basis of additional validation testing for the elderly population was increased arterial stiffness with aging [20], which is a manifestation of CKD including during the predialysis period [21]. European Society of Hypertension Practice 2010 Guidelines for HBPM recommended specific validation for end-stage renal disease [5]. Arterial stiffness can influence the correspondence between readings taken by mercury sphygmomanometers and oscillometric devices $[4,22]$. Although arterial stiffness can affect accurate BP measurement, there are limited data regarding the use of automated oscillometric devices in CKD. All of the sphygomanometers tested in these studies were upper arm devices used either for HBPM or 24-hour ambulatory BP monitoring. Despite being commonly used, validation of a wrist device has not yet been conducted in a CKD population. Although there were studies among hemodialysis patients $[23,24]$, to date, only one upper arm automated home sphygmomanometer has been validated for dialysis patients according to the European Society of Hypertension International Protocol with subject recruitment modifications in 2007 [22]. Peixoto et al. [25] validated the use of an oscillometric ambulatory BP monitor among hemodialysis patients in 1999. They also showed that the presence of non-functioning arteriovenous grafts and fistulas in the ipsilateral arm did not alter these results significantly [25]. We believe more validation studies for CKD patients are needed in the current HBPM era. Additional validation studies aiming to enhance the accuracy requirements is an important issue. Experts agree that it would be important to have at least two validation studies conducted in different centers and with various populations [10].

To our knowledge, this is the first study investigating validation of an oscillometric device in stage 3-5 predialysis CKD patients, a condition affecting about $5 \%$ of the general adult population. The Omron M3 Intellisense device fulfills the validation criteria of the ESH-IP2 when properly used for this special group. The only limitation of our study was its failure to enroll 10-12 patients in the highest DBP categories as recommended by the ESH-IP2 protocol [9]. Since most of the patients enrolled to the study were in regular follow-up in the nephrology clinic and the mean number of antihypertensive medications used by the patients was 2.7 per day, this was not surprising. Another reason for failing to enroll patients in the highest DBP categories could be arterial stiffness causing high systolic BP (SBP) and low DBP. The purpose of increasing from 33 to 66 subjects was to decrease the effect of this limitation. In addition, the ESH-IP2 protocol allows reasonable adjustments for special groups. Measurement of arterial stiffness of the subjects involved in the 
study could be useful, but it is not required for the standard validation protocols.

The validation study of the Omron M3 Intellisense device for the general population was carried on according to the International Protocol [10], but the device also fulfills the validation criteria of the ESH-IP2 which are tighter. At entry, the mean BP values were higher (150 vs. 144) for SBP and lower (82 vs. 88) for DBP in our study than in the general population study, in which the overall performance of the device was slightly better (table 5). The mean age of the participants was 11 years older $(63$ vs. 52) in our study and 31 of the 66 subjects were older than 65 years. In addition, 11 of the subjects had diabetes mellitus in which arterial stiffness also increases in the CKD group.

\section{Conclusion}

This study validates the Omron M3 Intellisense upper arm device for stage 3-5 CKD patients in addition to the general adult population. New validation studies investigating other oscillometric sphygmomanometers for CKD patients and the involvement of nephrologists in these studies have great potential to increase patient care in CKD.

\section{Disclosure Statement}

The authors have no conflicts of interest to disclose.

\section{References}

1 Bakris GL, Ritz E: The message for World Kidney Day 2009: hypertension and kidney disease: a marriage that should be prevented. Kidney Blood Press Res 2009;32: $67-70$.

$\checkmark 2$ Sarafidis PA, Li S, Chen SC, Collins AJ, Brown WW, Klag MJ, Bakris GL: Hypertension awareness, treatment, and control in chronic kidney disease. Am J Med 2008;121: 332-340.

3 Pickering TG, Miller NH, Ogedegbe G, Krakoff LR, Artinian NT, Goff D; American Heart Association; American Society of Hypertension; Preventive Cardiovascular Nurses Association: Call to action on use and reimbursement for home blood pressure monitoring: a joint scientific statement from the American Heart Association, American Society of Hypertension, and Preventive Cardiovascular Nurses Association: J Cardiovasc Nurs 2008;23:299-323.

4 Pickering TG, Hall JE, Appel LJ, Falkner BE, Graves J, Hill MN, Jones DW, Kurtz T, Sheps SG, Roccella EJ; Subcommittee of Professional and Public Education of the American Heart Association Council on High Blood Pressure Research: Recommendations for blood pressure measurement in humans and experimental animals. Part 1 : Blood pressure measurement in humans: a statement for professionals from the Subcommittee of Professional and Public Education of the American Heart Association Council on High Blood Pressure Research. Hypertension 2005;45:142-161.
5 Parati G, Stergiou GS, Asmar R, Bilo G, de Leeuw P, Imai Y, Kario K, Lurbe E, Manolis A, Mengden T, O'Brien E, Ohkubo T, Padfield P, Palatini P, Pickering TG, Redon J, Revera M, Ruilope LM, Shennan A, Staessen JA, Tisler A, Waeber B, Zanchetti A, Mancia G: European Society of Hypertension Practice Guidelines for home blood pressure monitoring: J Hum Hypertens 2010;24:779-785.

6 Association for the Advancement of Medical Instrumentation. American National Standard for Electronic or Automated Sphygmomanometers: ANSI/AAMI SP10 - 1993. Arlington/VA, AAMI, 1993.

7 O’Brien E, Petrie J, Littler W, DeSweet M, Padfield PL, Altman DG, Bland M, Coats A, Atkins N: The British Hypertension Society Protocol for the evaluation of blood pressure measuring devices. J Hypertens 1993;11 (suppl 2):S43-S63.

8 O'Brien E, Pickering T, Asmar R, Myers M, Parati G, Staessen J, Mengden T, Imai Y, Waeber B, Palatini P, Gerin W; Working Group on Blood Pressure Monitoring of the European Society of Hypertension: Working Group on Blood Pressure Monitoring of the European Society of Hypertension International Protocol for validation of blood pressure measuring devices in adults. Blood Press Monit 2002;7:3-17.

$\checkmark 9$ O'Brien E, Atkins N, Stergiou G, Karpettas N, Parati G, Asmar R, Imai Y, Wang J, Mengden T, Shennan A; Working Group on Blood Pressure Monitoring of the European Society of Hypertension: European Society of Hypertension International Protocol revision 2010 for the validation of blood pressure measuring devices in adults. Blood Press Monit 2010;15:23-38.
10 Asmar R, Khabouth J, Topouchian J, El Feghali R, Mattar J: Validation of three automatic devices for self-measurement of blood pressure according to the International Protocol: The Omron M3 Intellisense (HEM-7051-E), the Omron M2 Compact (HEM 7102-E), and the Omron R3-I Plus (HEM 6022-E). Blood Press Monit 2010;15: 49-54.

11 Levey AS, Coresh J, Balk E, Kausz AT, Levin A, Steffes MW, Hogg RJ, Perrone RD, Lau J, Eknoyan G; National Kidney Foundation: National Kidney Foundation practice guidelines for chronic kidney disease: evaluation, classification, and stratification. Ann Intern Med 2003;139:137-147.

12 Agarwal R, Peixoto AJ, Santos SF, Zoccali C: Out-of-office blood pressure monitoring in chronic kidney disease. Blood Press Monit 2009;14:2-11

13 Akpolat T: Home sphygmomanometers: what should a nephrologist know? J Nephrol 2011:24:300-306.

14 Funahashi J, Ohkubo T, Fukunaga H, Kikuya M, Takada N, Asayama K, Metoki $\mathrm{H}$, Obara T, Inoue R, Hashimoto J, Totsune K, Kobayashi M, Imai Y: The economic impact of the introduction of home blood pressure measurement for the diagnosis and treatment of hypertension. Blood Press Monit 2006;11:257-267.

15 Agarwal R: Managing hypertension using home blood pressure monitoring among haemodialysis patients - a call to action. Nephrol Dial Transplant 2010;25:1766-1771.

16 O’Brien E, Atkins N: State-of-the-market from the dableducational.org website. Blood Press Monit 2007;12:377-379. 
17 Akpolat T: Obesity, hypertension and home sphygmomanometer cuffs. Eur J Intern Med 2010;21:338-340.

-18 Coleman A, Stephen Steel S, DeGreeff A, Shennan A: Validation of the Lloyds Pharmacy BP11 oscillometric blood pressure monitor according to the International Protocol of the European Society of Hypertension. Blood Press Monit 2010;15:163-166.

19 Akpolat T: Proposal of a method for the evaluation of inaccuracy of home sphygmomanometers. Blood Press Monit 2009;14:208215.
20 Omboni S, Riva I, Giglio I, Caldara G, Groppelli A, Parati G: Validation of the Omron M5-I, R5-I and HEM-907 automated blood pressure monitors in elderly individuals according to the International Protocol of the European Society of Hypertension. Blood Press Monit 2007;12:233-242.

21 Kidney Disease: Improving Global Outcomes (KDIGO) CKD-MBD Work Group. KDIGO clinical practice guideline for the diagnosis, evaluation, prevention, and treatment of chronic kidney disease-mineral and bone disorder (CKD-MBD). Kidney Int 2009;76(suppl 113):S1-S130.

-22 Thompson AM, Eguchi K, Reznik ME, Shah SS, Pickering TG: Validation of an oscillometric home blood pressure monitor in an end-stage renal disease population and the effect of arterial stiffness on its accuracy. Blood Press Monit 2007;12:227-232.
23 Semret M, Zidehsarai M, Agarwal R: Accuracy of oscillometric blood pressure monitoring with concurrent auscultatory blood pressure in hemodialysis patients. Blood Press Monit 2005;10:249-255.

24 Czarkowski M, Staszków M, Kostyra K, Shebani Z, Niemczyk S, MatuszkiewiczRowińska J: Determining the accuracy of blood pressure measurement by the Omron HEM-907 before and after hemodialysis. Blood Press Monit 2009;14:232-238.

25 Peixoto AJ, Gray TA, Crowley ST: Validation of the SpaceLabs 90207 ambulatory blood pressure device for hemodialysis patients. Blood Press Monit 1999;4:217-221. 